\title{
SYMBOLISM DISCUSSION OF THE ANGELS AND DEMONS MOVIE
}

\author{
Jimmi $^{* 1}$, Juniato Sidauruk ${ }^{* 2}$ \\ jimmi.jmm@bsi.ac.id ${ }^{* 1}$, junianto.jnd@bsi.ac.id ${ }^{* 2}$ \\ Faculty of Communication and Language ${ }^{{ }^{1}}$, Faculty of Technology and Informatics ${ }^{* 2}$ \\ University of Bina Sarana Informatika ${ }^{* 1,2}$
}

\begin{abstract}
This research focuses on symbolism, which appeared in Angels and Demons Movie. There are various symbols shown through this Angels and Demons Movie. Most of the symbolism has a different meaning to be analyzed. The discussion covers on symbolism specifically on types and meaning on it. This research uses qualitative-described research. The writer accomplishes it by getting the data needed through this movie. Collect the relevant sources from library and e-book. Then continued to write any datas had found to be analyzed. The literary symbol means the Illuminate is still alive. They will take revenge on the Vatican and as the first direction to go to the first altar of science made by Raphael Santi. The religious symbol means the Illuminate will kill the four of the cardinal at the four altars with an angel as a clue. Map or cartography means to find the altar of Illuminate that dispersed in the Vatican City. The conclusion of the research is finding five types of symbolism, whereas only three symbolisms are suitable for this research, discover the meaning of every single symbolism found.
\end{abstract}

Keywords: Symbolism, Movie, Literature

\section{INTRODUCTION}

Watching movie is the most entertaining activity. People are free to choose whatever movie they like to watch later. The movie can relieve the stress of people from daily routines they have done. Movie is a tool to reach satisfying and feeling comfortable to relax and enjoy following the story inside it. People prefer to watch a movie by going to the theater or television due to they can see the character directly through the screen. They can hear what the character has spoken through the movie, they can also see the view which appeared in the movie, and the last they can get the feeling or some messages of the story been watched, such as happy ending or sad ending.

There are many genres of movies that have produced. These genres would make people like to watch the movie based on what they have chosen. Like other literary works, the movie also has a plot, setting, and character that will make people interested in watching until the end.

Many movies present the genres by giving the theme such as love, romance, friendship, betraying, mystery, and humor. But not many movies can present the story given about symbolism as appeared in Angels and Demons Movie. Symbolism, in this case, would like to bring the reader that every single image or picture that appeared in the movie must give particular meaning. The main priority for the writer is to investigate the meaning behind every single symbol. 
The symbolism, as mentioned above, presented in Angels and Demon Movie. This movie tries to present and show various symbolism found during the plot of this movie. The plot is a scholarly term characterized as the occasions that make up a story, especially as they identify with each other in an example, a succession, through circumstances and logical results how the peruser sees the story, or basically unintentionally. The plot can be a progression of occasions that are tied dependent on the connection of its creation in sequential occasions. They are identified with another dependent on the reason impact from the earliest starting point of the story until the end. One is commonly intrigued by how well this example of occasions achieves some imaginative or enthusiastic impact.

Many things can improve the plot of this story. One of them is Ambigrammatic symbols, as seen in Angels and Demons Movie. The symbol could be a person, place, action, word, or thing that represents something other than itself. The symbol also has many meanings and unique, which makes people interested to know further about this. The writer chooses Angels and Demons movie because this movie tells about the problems that happened in Vatican City, where Pope Pius died. The meeting has assembled in a bolted space to pick his replacement among four cardinals named "Preferiti". There are two problems to answer. First, What kinds of symbols appear in the Angels and Demons movie?. Second, What are the meanings of the symbol in the Angels and Demons movie?.

\section{LITERATURE REVIEW Definition of Literature}

According to (Chambers 2004), "Literature is written material, such as novels, poems, and plays that is valued for its language and content." It means that literature is a kind of works that valued for its language and content. (Wellek \& Warren, 1954) explained, Literature is one realization ideas which have the characteristics and totally dependent by authors themselves. Literature also represents life in large measure." It means the literary works tend to bring some ideas and minds that would appear into the character of an actor or actresses. This will bring the character to play the cast based on the role they will act to. It cannot be ignored that the literary works representative of the life sequence at any circumstances. By literary work, whether novel or movie, the audience can feel satisfaction and enjoyable moment while they spent their time watching movie or reading novels.

Quoted by (Culler, 2001) " Artistic work is a phonetic occasion which extends an anecdotal world. It incorporates speaker, entertainers, occasions, and a suggested crowd" It means that literature is the name of an organization with a social purpose that gives a reason to us and to believe that something result of our reading and literature refers to imaginary rather than historical individuals.

To conclude, literature describes written or spoken material that related to intellectual capital, especially focusing on work meaning. Literature is contextual and theoretical bases to help the reader understand the complex relationship that exists among various genres of literature, such as examine novel, short stories, plot, and poems. Thus its goals are about to teach readers to recognize specific 


\section{Jimmi $^{* 1}$, Juniato Sidauruk ${ }^{* 2}$ \\ SYMBOLISM DISCUSSION OF THE ANGELS \\ AND DEMONS MOVIE}

attributes or effective literature. Literature gives reason for human life to understand and exercise language.

\section{Definition of Movie}

In (Buckland, 2009) "Movie is the blend of picture, development, and sound is clearly something very secretive in its consequences for people, practically mystical, frequently portrayed as a sort of multiplying of life itself, a type of eternality, a perpetual and forever captivating mirror." In other words, it is the composite of picture, act, and sound that clearly something very puzzling, almost magical. But at the same time, it also based on the real. According to (Klarer, 2004), movie as a semi textual genre both effect on writing and artistic criticisms. The movie is foreordained by abstract methods, and on the other hand, a scholarly practice created specific highlights under the effect of the movie." It can be said that movie is a part of literature with literary technique and development of literature itself is under the influence of the movie. (Bazin \& Andrew, 2004) explains that, "Movie is viewed as a significant piece of a wellspring of famous diversion and ground-breaking strategy for teaching." From the statement above, it means that movie is a popular entertainment and it can be an important art for education also.

In view of the proclamation above, it tends to be closed that a movie is the composite of picture, act, and sound that clearly something very secretive, almost magical. But at the same time, it is also based on the real by using literary technique and development of literature itself under the influence of the movie. It also popular entertainment and it can be an important art for education.

\section{Definition of Plot}

Based on (Baldick, 2001) "Plot is the example of occasion and circumstance in a story or emotional word as a chose and mastermind however underlined relationship normally of circumstances and logical results among occurrences and to inspire a specific sort of enthusiasm for the peruser or crowd, for example, shock or anticipation." It can be said that a plot is the grouping of occasions that underscored connections ordinarily of circumstances and logical results among occurrences and to make the reader or audience interested in the story.

In Stanford's opinion (2006:31), " Plot is the arrangements of occasions and exercises in an artistic work." It means that the plot is a pattern of events to build up a story in a literary work. So, making a good plot would make people have a curiosity about what is a story about; they wonder to know the next event or scene will show in this movie, and of course, to know how the end of the story is whether happy ending or sad ending. In light of the information above, it tends to be presumed that a plot is the grouping of occasions to develop a story that emphasized relationship cause and effect between incidents and events to make audiences interesting in the story.

\section{Definition of Symbol}

Chambers, (2004) says that, "Symbol is a thing that speaks to or represents another, generally something concrete or material speaking to a thought or feeling, such as, the shading red speaking to risk." In other words, an image is a thing that represents idea or emotion. According to Webster (2005:14502, "Symbol is a composed or printed mark, letter, shortening, and so on representing an item, 
quality, process, amount, and so forth., as in music, science, or science." It can be said a symbol is written that representing an article, quality, process, and amount.

Another opinion about symbol is from Griffith (2006:69), " An image is something speaks to something different. Words, for instance, are images. Be that as it may, in writing, an image is an article that has importance past itself. Images, be that as it may, are not illustrations; they are not analogies that explain deliberations. It means a symbol is an object that concrete and has abstract meanings. However, symbols are not representations, and they are not analogies that explain reflections. MacMillan (2009) explains that "Symbol is an imprint, letter, number, and so on used to speak to something, for instance, in science or music." It means a image is written that used to represent something.

According to Keller (2013: Sorts of images in writing), "A scholarly image is something that has more noteworthy importance than its negligible exacting noteworthiness in a story or sonnet. This representative importance might be explicit to the writer or progressively across the board, running from social noteworthiness to widespread affiliation. The whale in Herman Melville's tale "Moby Dick," for instance, is frequently viewed as an indication of underhandedness, in spite of the fact that that significance is once in a while connected to whales in different works. A rose, then again, is viewed as an indication of sentiment the world over. Numerous different images in writing are similarly far reaching." It means a symbol is something in literary work that has greater meaning and may be specific to the author. And other symbols in literature are also equally widespread.

Based on Lebednik (2013. Five various types of images), "An image depicts something that speaks to something different. Images go from those that include a level of interpretive multifaceted nature to comprehend to those that give a genuinely direct portrayal of the objects or actions those symbols represent and incorporate a variety of mid-range levels of analytical complexity in between those two extremes." It can be said a symbol is something that describes something else and has the range that involves a degree of interpretive complexity to understand it. In view of the announcement above, it very well may be reasoned that that symbol is written that represents something, an idea or emotion, and in general not stand for anyone meaning nor for anything absolutely defined, but can stand for an object, quality, process, quantity. The symbol also is something in literary work that has greater meaning and may be specific to the author, a concrete object that has abstract meanings. However, symbols are not representations, and they are not analogies that explain deliberations

\section{Kinds of Symbols}

Based on Waluyo (2003:5) said a symbol is classified into three things, they are: 1. The shading image gives the extra importance to upgrade the genuine significance (mean the indication). For instance, dark shading is an image of the distress, and white is an image of modesty, yellow is an image of dedication, blue is an image of desire, etc. 2. The sound image is a particular importance made by sound or mix of specific sounds. For instance, the Gamelan sound carries us to the idea of center Java and East Java. 3. Environment image is the event or situation which is not described as what it is, but replaced with other situation.

Another opinion about kinds of a symbol is from Griffith (2006:69), there are two sorts of the symbol: Open images are regular, those that the vast majority 


\section{Jimmi $^{* 1}$, Juniato Sidauruk ${ }^{* 2}$ \\ SYMBOLISM DISCUSSION OF THE ANGELS \\ AND DEMONS MOVIE}

specifically culture or network would perceive as importance something genuinely positive. Such as open images are cross, the star of David, the American hawk, banners of nations, the shading red (for stop) and green (for go), and the skull and crossbones. Private images are one of a kind to an individual or to a solitary work. Just from hints in work itself would we be able to become familiar with the representative estimation of the article.

According to Keller (2013.Kinds of symbols in literature), there are four kinds of the symbol. First, Hues regularly have emblematic importance in artistic works. Red is typically connected with life, risk, or enthusiasm. Second, Natures, numerous parts of nature have conventional emblematic implications. Third, Bearings. The four compass bearings are viewed as images of various things, contingent upon the work being referred to. Fourth, Creatures. Numerous creatures have since quite a while ago had representative essentials.

Based on Lebednik (2013. Five different kinds of symbols), there are five kinds of symbols. First, Religious. Religious symbols may find both in private and in community worship. Second, Literary. A literary symbol may represent something regard to an individual character in the literary work, or it can represent something about an entire culture or subculture. Third, Dreams. Those who study dream analysis have only relatively recently even admitted that any dreams exist that do not contain symbolic meanings. Fourth, Map or Cartography. On maps, you will find symbolic representations of locations such as lakes, oceans, or deserts. Fifth, music. In music, you will find at least two different categories of symbols. Perhaps the most recognized among those not seriously involved with music involves the symbol system used for sheet music. For vocalists and instrumentalists, sheet-music symbols such as notes, musical staffs, clefs, and rests represent the succession and duration of the notes and the pauses that make up the melodic elements of a musical piece. Dancers also make use of musically related symbols in a separate symbol system called choreography, in which a sequence of pictorial symbols drawn on paper represents the sequence of movements that make up a dance.

In light of the announcement above, it very well may be finished up that symbol is not only colors, direction, and maps as the people have known, but many symbols in this world that the people unknown such as nature, animals, and signs. However, each expert presented different perceptions to determine the symbols, so resulting from the different itself in each symbol that exists and found.

\section{Definition of Ambigram}

Quoted by (Riders et al., 2013), "An ancient art of ambigrams can be read from more than one perspective-the word reads the same upside down, or backward and forwards." It means that Ambigram is the symmetry words that can be read upside down or backward and forwards. According to Gef (2005:1), " An ambigram is a word or a gathering of words which can be perused in any event two unique ways. The most common are symmetric under a revolution of 180 degrees (i.e., they look a similar topsy turvy) or under a vertical hub reflection (i.e., they appear to be identical in a mirror)". In can be said that the Ambigram is rotational symmetry, words that can be read without any differences in the text, even if it read in rotation 180 degrees. 
Another opinion about Ambigram is from (Riders et al., 2013). " An Ambigram is a typographical creation that presents at least two separate words inside the equivalent physical space." It means that Ambigram is s writing that shows two or more words without any differences physical. In light of the announcement above, it very well may be finished up that Ambigram is the symmetry words that can be read upside down or backward and forwards or in rotation 180 degrees without any differences physical on the text.

\section{RESEARCH METHOD \\ Research Design}

This investigation utilizes an expressive subjective strategy. As indicated by Ragin (Ten Have, 2004), offers complex portrayals and attempts to explain networks of significance." This strategy is going to gather the information, particularly the collocation information, through the film, is picked. At that point keep on gathering the vital information ground hypothesis are through library look into. The writer is not just viewing the film yet additionally looking through the books, which correspond with this paper been inquired about to help and give conversation explicitly. Subsequent to viewing the film over and over, the creator could get significant focuses in the film and summarize those focuses been found so it can be easier to analyze it.

\section{Data Source of Research}

This research is focused on Symbols, which appeared in the Angels and Demons movie. The writer finds three symbols that suitable based on the Lebednik theory. The data sources for this research are Angels and Demons Movie and some relevant theories in searching the meaning of the symbols.

\section{Instrument of Research}

This research mainly focuses on finding symbols and their meaning. The research requires a good instrument to obtain the data. The instruments are being mentioned, such as the file of Angels and Demons Movie, the laptop, e-book as a main priority book source, notes. So, the writer is the main instrument to collect and analyze the data been taken as it not possible to use other research instruments.

\section{Data Collection}

This research does several steps to get a good result: First, the writer watches Angels and Demons Movie over and over, and then taking notes that the writer considers is important and needs it. Second, the writer looks for any book references such as e-book that suitable for the research of this movie. Third, the writer categorized the symbol that the writer had found based on the relevant theory. Fourth, the writer begins to analyze that data carefully.

\section{Data Analysis}

In the next steps, the writer begins to analyze the data based on the relevant book sources that the writer had collected. The steps as follow: First, the writer shows the data have found. Second, the writer does an in-depth analysis of every single data by using relevant book sources, especially Lebedink's theory. 


\section{Jimmi $^{* 1}$, Juniato Sidauruk ${ }^{* 2}$ \\ SYMBOLISM DISCUSSION OF THE ANGELS \\ AND DEMONS MOVIE}

Third, the writer chooses Angels and Demons movie because, according to the writer, they found several symbols that appeared in this movie. This symbol has several meanings, and it makes it curious to dig this data deeper. Fourth, the writer shows the kinds of symbols and analyzes the meaning of that. Fifth, the writer classifies the kinds of symbols based on Lebednik's theory and giving analysis for every single symbol found.

\section{FINDING AND DISCUSSION}

\section{Finding}

\section{Kinds of Symbols Appeared in Angels and Demons Movie}

Based on theory from Lebednik, there are five kinds of symbols; Religious Symbols, Literary Symbols, Dreams, Map or Cartography, and Music. After the writer watches this movie over and over, the writer can get the gist that the writer finds three kinds of the symbol only. These symbols suitable based on Lebedink's theory. The symbols will explain as follow:

\section{Literary Symbol}

\section{Data 1}

In this part, Langdon and Vincenzo are trying to find they looked for about the paper. They found a paper in the ornate text that describes Illuminati. The character Vincenzo seems to get closer to the paper specifically, and it writes on the back up of the paper. Both of them look strange about this paper until Vincenzo tries to turn the paper upside down. They feel shocked while they know this paper, especially the word of Illuminati has similar words as they move upside down.

To get this word by Illuminati word, the character Langdon assumes that this Illuminati also is known as Ambigram. This Ambigram is a common symbol such as a Jewish star, Yin and Yang for the Chinese, and a swastika. Langdon keeps trying to dig deeper until this character briefly to conclude that people have been looked for this Illuminati Ambigramatic symbol for about four centuries, the longest time period at that time. This symbol has been tried to create a new word by another modern semiologist, but it never succeeds. Even they try to break it by the computer; the result is nothing. Finally, they had concluded this Illuminati is a myth.

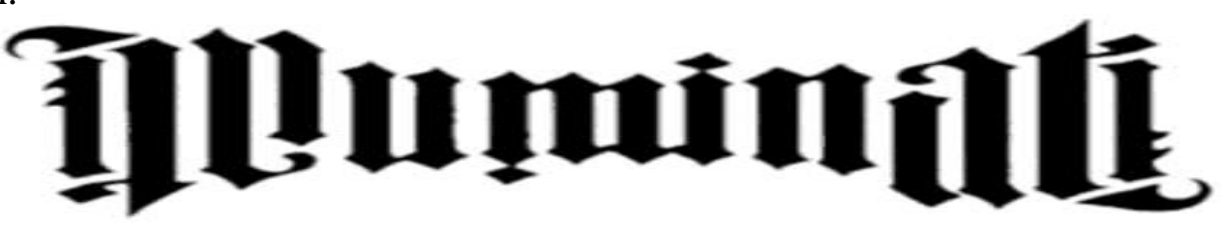

Figure 1. Ambigram Word

(duration : 00:12:09)

Based on Christine's theory, the literary symbol may represent something with regard to an individual character in the literary work, or it can represent something toward an entire culture or subculture. So, the kind of symbol from the data above is a literary symbol. Because the symbol that shows in data 1 is Ambigram that represents the subculture about Illuminati in Angels and Demons Movie.

Data 2 
In this scene describes Langdon, Vittoria, and Olivetti are argue to the paper they found. There are arguing about Cross Rome, the mystic element sun fold. Vitoria and Olivetti looked like they did not disagree with what Langdon was thinking of. Both sides of a bit of challenge for what they found. Langdon tries to explain it even though both of them were still on their stands.

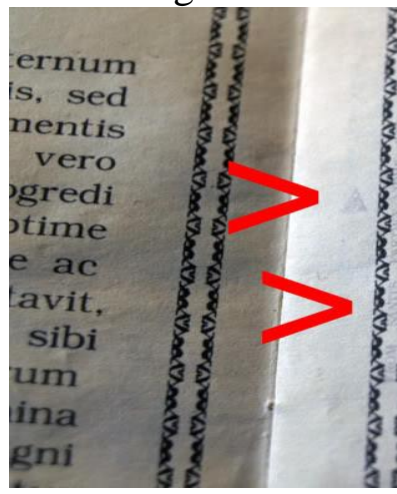

Figure 2. Diagramma

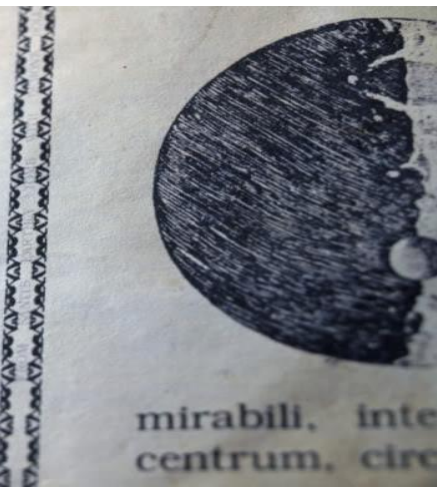

(duration : 00:36:55)

The literary symbol may represent something about an individual character in the literary work. The reason is why the data included because the symbol is used in the form of sentences of the literary works. It represents where the altar of Illuminati. It is a poem made by John Milton. The poem found in Diagramma book, the works of Galileo Galilei. It is made for giving a clue for new members of Illuminati to find the Illuminati's church, a place where the members of Illuminati gathering and discussing are about the Catholic Church.

\section{Data 3}

LANGDON (continued) : " My Italian's awful, what does this note say? Close to the section for The Ecstasy of St. Teresa?"

Chartrand tries to keeps his minds instead, some books give him big pressure to see in more specifically through the books.
CHARTRAND
LANGDON
: "Moved at the recommendation of the craftsman."
: "Moved to another congregation? At Bernini's proposal?"

Chartrand gets difficult for Air and makes him cannot go along with it.

CHARTRAND

: "I don't have the foggiest idea."

Langdon reverses the page to certain photos of the figure.

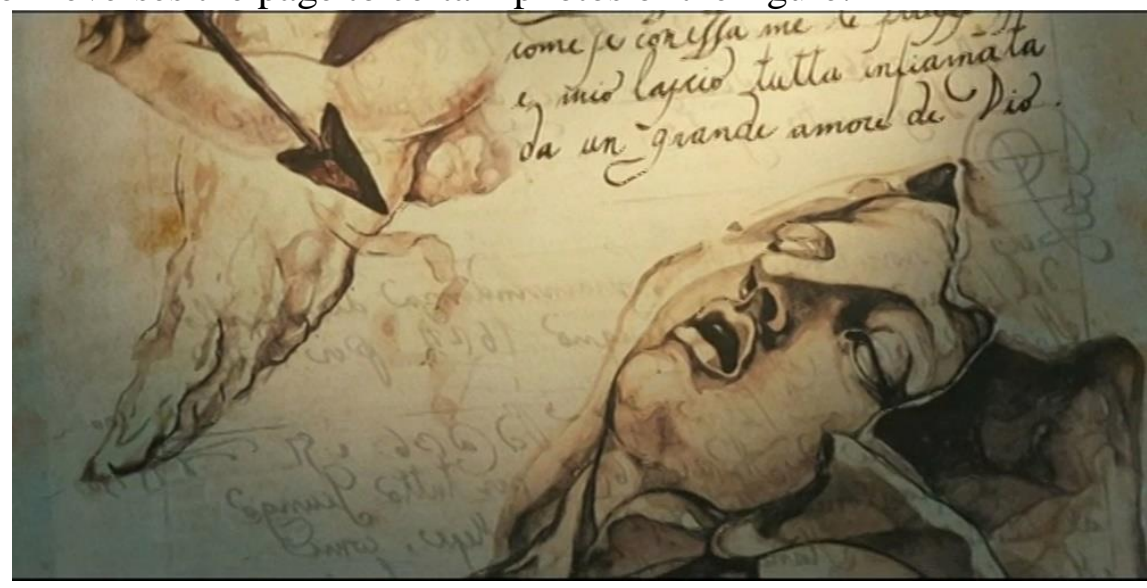

Figure 3. Ecstasy Saint Teresa 


\section{Jimmi $^{* 1}$, Juniato Sidauruk ${ }^{* 2}$ \\ SYMBOLISM DISCUSSION OF THE ANGELS \\ AND DEMONS MOVIE}

(duration : 01:01:97)

This data is a literary symbol because it was found in literary works. It is about Ecstasy Saint Teresa, and in the literary works, there is a word, Seraphim, which is meant by the fiery one. Fire is the next clue to find the last church or altar of science.

Religious

Data 4

LANGDON (cont'd) : " Habakkuk and the Angel."

VITTORIA

: "Habakkuk?"

LANGDON : "The prophet who anticipated the demolition of the earth."

"This is the main marker."

His step was getting closer, and he has been studying it carefully.

LANGDON (cont'd) : " Let holy messengers manage you on your grand journey..."

He looks over the statue slowly with them. The angel's statue shows with an innocent face. The arm is downward, right hand. This means the angel's statue can be defined as outstretched, one finger extended, showing the way pointed.

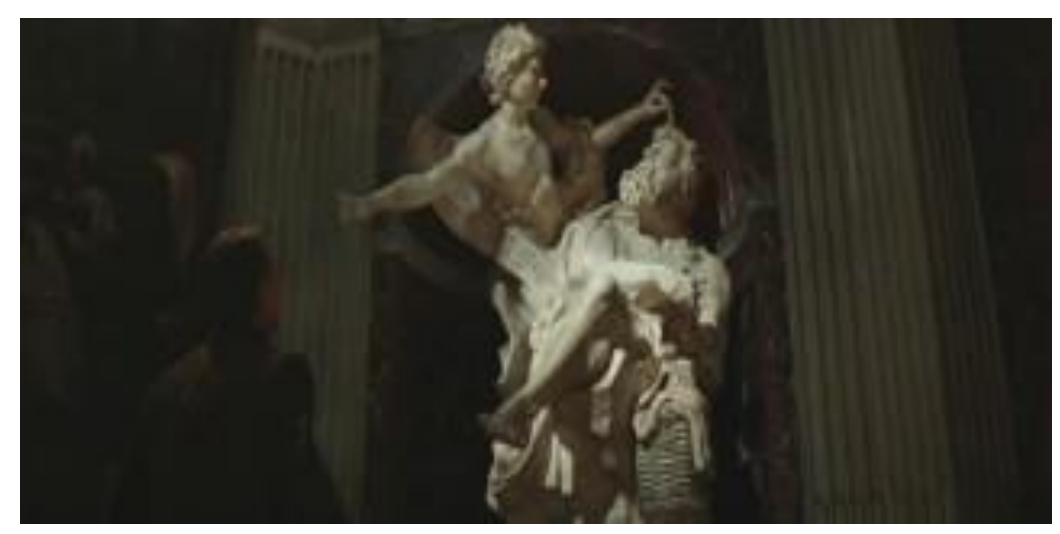

Figure 4. Habakkuk and the Angel

(duration : 00:47:92)

The reason is that there is any statue of Habakkuk and an Angel. The Habakkuk is a prophet who anticipated the demolition of the earth.

\section{Data 5}

Two characters, Langdon and Vittoria, continue to investigate to next statue. In this situation, Vittoria gets confused while she looks at the statue around her. This is because many statues she found and make her cannot point the chosen one. Langdon keeps searching for anything in that place while he started to look at his watch. The character Langdon starts to feel freezes started from his feet. He gets to move back as he looked at fresco carved into the square on his below.

Langdon assumes that this fresco carved as Bas relief. Both Langdon and Vittoria are going around the carving. The Bas relief is another half of the sculpture, and it is related to Air. When they found it, they are trying to pass the way where many people around them. These people have to make commotion while the character Langdon tried to break this uniquely carving in the rock of square. 


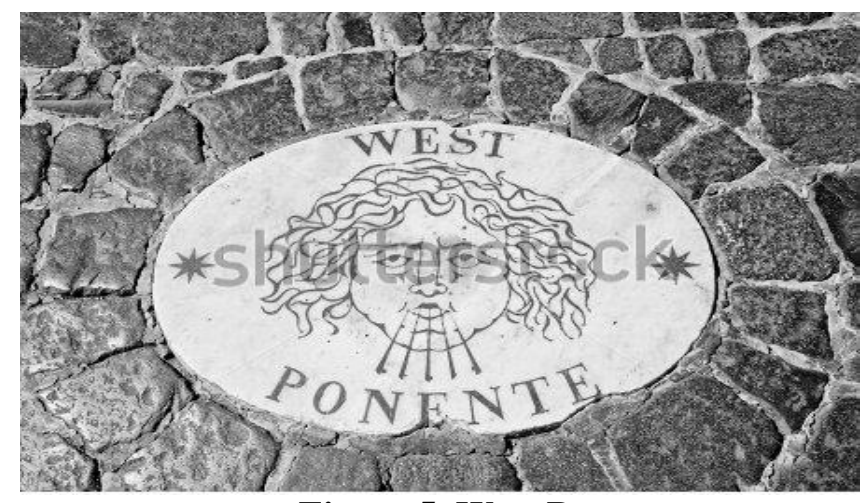

Figure 5. West Ponente

(00:51:57)

It is West Ponente or known as the west wind. It also recognized as "Respiro di Dio." Breath of God. Bernini, one of Illuminatus, designed it.

\section{Data 6}

Langdon and Vittoria slither to the Church of Illumination. Both of them find an interesting view on it, such as the embellishments, though faded that familiar to symbology. Not just those things they have found, they also get planet frescoes and Pyramids.

Langdon agrees for what Vittoria has said that they must find the canister. The church has been made Langdon fond of that place. The center of the room has furnace which still on. Thus, there are four Illuminati brands in that place. They wiped their face cleanly and placed back in a molded of velvet issues. He is ravishing of the place they found. The place makes Langdon fall in love with it, such as spots with an empty slot in each center around the place covered by the four brands.

Langdon and Vittoria begin to argue with each other. The man has a strong feeling that it must have the fifth brand over the place they visited. Langdon touches the curvature of the velvet and makes it difficult to solve this puzzle.

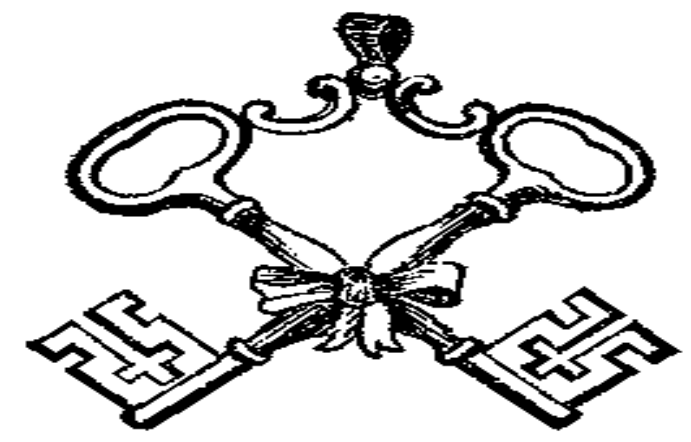

Figure 6. Two Crossed Keys

(duration : 01:33:80)

The reason why this data is a religious symbol because two crossed keys are a symbol of the papacy. And the Pope is a leader of Catholicism. So this data is a religious symbol.

Map or Cartography Symbol

Data 6

CAMERLENGO : " Mr. Langdon, you've been correct up until this point, assuming belatedly, about the Path. It's presently nine- 
fifteen, how rapidly would you be able to locate the following church?"

Langdon take a gander at the guide which is spread out over the work area

LANGDON : " The line of the breath in the cutting focuses due east, straightforwardly away from Vatican City, yet there are five lines, so there's space for blunder."

(duration : 00:57:57)

Data 7

ROMAN'S PLOICE : "Teacher, I have to realize what you saw here."

LANGDON : "Fire and passing. Give me where Santa Maria del Popolo is."

(the police officer does not comprehend at all)

The police begin to the point of the spot in the center-bellow. His eyes increase to look around until he grabs the police by using some pens that he took from man's pocket. He draws about clues he found, such as drawn from north toward the south and interfacing two holy places, while the police have highlighted.

Next, he will use the pen as a point to show to the eastern side of the map.

As Christine says in theory, "On maps, you will find symbolic representations of locations" in the data 5, the character uses the map to find the church, and the character points the symbol church on the map. Data 7 of the character uses a map to find the church and the character. It marks the symbol of the church on the map and draws a line straight over the guide. So, the data 5 and the data 7 are included in map or cartography as Christine says in the theory because the character finds symbolic that representations of the church.

\section{Discussion \\ Meaning of the Symbols in Angels and Demons Movie \\ Literary Symbols \\ Data 1}

The symbol that shows in data 1 has meant that the Illuminati is still alive. As the Illuminati promise, they will take revenge on the Vatican. The Illuminati will treat the Vatican as the Vatican treated the Illuminati in the past by branded them with the Vatican symbol. Because of that, the Illuminati kidnapped the Preferiti or the four cardinals, and they gave the word Illuminati that is written in Ambigram to known every people in the Vatican that they are still alive. Because only the Illuminati who are using Ambigram as a symbol.

\section{Data 2}

From Santi's natural tomb with an evil spirit's gap, it means that the main raised of science is in a chapel, which has a demon's hole as a tomb, and the the devil's gap is an antiquated term for a monstrous entombment cavity situated in a sanctuary, underneath another tomb. The tomb was designed by Santi Raphael, the anonymous Illuminati master. It also means that the primary special raised area of science is at the Chigi Chapel, and it used to be called Capella Della Terra, which implies Chapel of the Earth. 


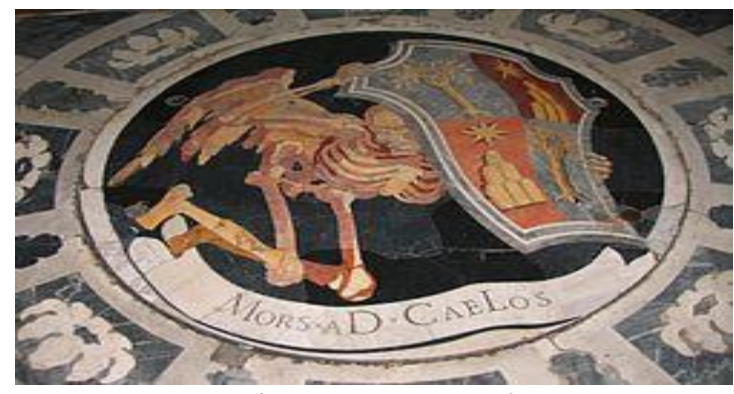

Figure 7. Demon's Hole

Cross Rome the spiritualist components unfurl, it implies that the four raised areas of science framed a major cross in Rome on the off chance that it found in a guide. The cruciform is a definitive Illuminati duality. It is a strict image shaped by components of science. Galileo's Path of Illuminati is ascribing to both science and God.

The Path of light is laid the hallowed test. Let blessed messengers control you on your natural journey. It means that the direction to find the Path of Illuminati is clearest with an angel as a clue. The new member of Illuminati just needs to find the angel and solve the clue to find the church of Illuminati.

\section{Data 3}

The symbol that shows in data 3 is a paragraph that has a word fuòco that means fire. Despite the fact that the section was in Italian, the word fuòco seemed about multiple times:

... heavenly attendant's lance tipped with a state of fire ...

... heavenly attendant's head is exuding beams of fire ...

... lady excited by energy's fire ...

The angles light up by fiery and raised such a beacon, showing the way. It is Seraphim. Seraphim literally means "the fiery one." Because the fire is the next clue and the angel is Seraphim, which means the fiery one, Langdon seems that it is the next direction. And also, because the statue made by Bernini and was moved at Santa Maria Della Vittoria by suggesting of Bernini, so Langdon makes sure that the next altar in Santa Maria Della Vittoria.

\section{Religious}

\section{Data 4}

The statue means that the direction to find the next elements for the altar of science because it is made by Bernini, who is one of the members of Illuminati. $\mathrm{He}$ is an anonymous Illuminati master. As a literary symbol said before et heavenly attendants control you on your grand mission, it means that the statue of the heavenly attendants will guide Langdon to find the following special raised area of science. The statue of the heavenly attendants gives a direction from his finger. His finger pointed to let someplace outside of the church Langdon know where is the second altar of science.

\section{Data 5}

West Ponente is Bernini's tribute to the subsequent component, Air, an ethereal breeze blown from Angel's lips. Bernini had drawn a ground-breaking breath of air overwhelming outward from the Vatican, the Breath of God. Bernini had carved the air in five distinct gusts, five for Pythagoras and the Pentagram, and flanking the medallion were two shining stars, two for the duality of all things. It means that the place of West Ponente is the second altar of science, the 


\section{Jimmi $^{* 1}$, Juniato Sidauruk ${ }^{* 2}$ \\ SYMBOLISM DISCUSSION OF THE ANGELS \\ AND DEMONS MOVIE}

second place where the assassin will kill the second cardinal. And this relief also the second direction to find the third altar of science with the clue five gusts, two stars, ellipses, and symmetry.

Data 6

Two crossed keys, one gold and one silver, this speaks to the keys to the Kingdom of Heaven and is, from multiple points of view, the quintessential image of the papacy as an establishment and of its focal job inside the Catholic Church. Because the two crossed keys are a symbol of the papacy, the Illuminati used it for the brand of Camerlengo before they kill the Camerlengo and blow up the Vatican. The Illuminati want to show everyone that they will kill the Camerlengo and brand him like the four preferiti.

\section{Map or Cartography Symbol}

The meaning of the symbol in data 7 is to find the next Illuminati church where the Illuminati assassin will kill the cardinal. The character must find the realistic church and the way that closest from Vatican City before the Illuminati assassin killed the next cardinals. But there is something wrong. Because on the maps are five lines of Path of Illuminati. There must be four lines of Path of Illuminati, and it makes Langdon confused. So he must go to the Vatican archive again to collect the Path of Illuminati.

The meaning of the symbol in data 7 is to find the last church by marks the symbol of the church on the map. It draws a line straight over the guide until the character knows that the Illuminati has been made many churches in the Vatican, which are called as the altar of science. The church is always used by Catholic Rome without knowing that the church has made by Illuminati.

\section{CONCLUSION AND SUGGESTION}

Based on the theory from Christine Lebednik, there are five kinds of symbols, religious symbols, literary symbols, dreams, map, or cartography, and music. But the writer found three kinds of symbols only in Angels and Demons Movie. There are religious symbols, literary symbols, and maps, or cartographies. In Angels and Demons Movie, the writer finds 8 data about symbols. Religious symbols are three data, literary symbols are three data, and map or cartography are two data.

In the data that has found by the writer, the symbols in Angels and Demons Movie has a meaning. First, the literary symbol has a meaning that the Illuminate is still alive, and they will pay back with the Vatican. The literary symbol also has meaning as the first direction to go to the first altar of science made by Raphael Santi. The second symbol is a religious symbol that has a meaning that the Illuminati will kill the four of the cardinal at the four altars with an angel as a clue. Besides that, the religious symbol has a meaning that the first altar is the church of Santa Maria del Popolo or known as Capella Della Terra, which means Chapel of the Earth. The last symbol that the writer found is a map or cartography. The map also has meaning to find the altar of Illuminati that dispersed in the Vatican City.

\section{REFERENCES}

Baldick, Chris. 2001. The Concise Oxford Dictionary of Literary Terms. New York: Oxford University Press. Inc. 
Bazin, André. 2004. What is Cinema?. USA: University of California Press, LTD.

Buckland, Warren. 2009. Film Theory and Contemporary Hollywood Movies. New York: Routledge.

Chambers. 2004. Chambers Concise Dictionary. Chambers Harrap Publisher Ltd.

Collins. 2006. Collins Cobuild Advanced Learner's English Dictionary. Harper Collins Publisher.

Gef. 2005. Gef's Ambigram Gallery. Taken from http://www.gef.free.fr/ambigallery.html: 21 September 2012.

Griffith, Kelley. 2006. Writing Essays about Literature: a guide and style sheet. Boston: Thomson Wadsworth.

Keller, Mark. 2013. Kinds of Symbol in Literature. Taken from http://www.ehow.com/info_8534738 kinds-symbols-literature.html

Klarer, Mario. 2004. An Introduction to Literary Studies. London: Routledge

Lebednik, Christine. 2013. Five Different Kinds of Symbols. Taken from http://www.ehow.com/info_8469979_five-different-kinds-symbols.html

MacMillan. 2009. MacMillan English Dictionary. London: Mac Milan Publisher.

Prokhorov, Nikita. 2013. Ambigrams Revealed: A Graphic Designer's Guide To Creating Typographic Art Using Optical Illusions, Symmetry, and Visual Perception.

Stanford, Judith A. 2006. Responding to Literature Stories, Poems, Plays, and Essays. New York: Oxford University Press. Inc.

Waluyo, Herman J. 2003. Apresiasi Puisi untuk Pelajar dan Mahasiswa. Jakarta : Gramedia Pustaka Utama.

Webster, Merriam. 2005. Webster's New World College Dictionary. Cleveland, Ohio: Wiley Publishing, Inc. 